\title{
Clinical utility of circulating tumor cells in $A L K$-positive non-small-cell lung cancer
}

\author{
Vincent Faugeroux ${ }^{1,2}$, Emma Pailler ${ }^{1,2}$, Nathalie Auger ${ }^{3}$, Melissa Taylor $^{1,2}$ and Françoise Farace ${ }^{1,2}$ * \\ 1 INSERM U981 "Identification of Molecular Predictors and New Targets for Cancer Treatment," Institut Gustave Roussy, University of Paris-Sud, Paris, France \\ ${ }^{2}$ Translational Research Laboratory, Institut Gustave Roussy, Paris, France \\ ${ }^{3}$ Department of Biopathology, Institut Gustave Roussy, Paris, France
}

Edited by:

Stephen V. Liu, Georgetown

University, USA

\section{Reviewed by:}

Zhongxing Liao, The University of

Texas MD Anderson Cancer Center,

USA

Sunitha Nagrath, University of

Michigan, USA

${ }^{*}$ Correspondence:

Françoise Farace, Institut Gustave

Roussy, 114 rue EdouardVaillant,

Villejuif, Paris 94805, France

e-mail: francoise.farace@

gustaveroussy.fr
The advent of rationally targeted therapies such as small-molecule tyrosine kinase inhibitors (TKIs) has considerably transformed the therapeutic management of a subset of patients with non-small-cell lung cancer (NSCLC) harboring defined molecular abnormalities. When such genetic molecular alterations are detected the use of specific TKI has demonstrated better results (overall response rate, progression free survival) compared to systemic therapy. However, the detection of such molecular abnormalities is complicated by the difficulty in obtaining sufficient tumor material, in terms of quantity and quality, from a biopsy. Here, we described how circulating tumor cells (CTCs) can have a clinical utility in anaplastic lymphoma kinase ( $A L K)$ positive NSCLC patients to diagnose $A L K$-EML4 gene rearrangement and to guide therapeutic management of these patients. The ability to detect genetic abnormalities such ALK rearrangement in CTCs shows that these cells could offer new perspectives both for the diagnosis and the monitoring of $A L K$-positive patients eligible for treatment with ALK inhibitors.

Keywords: $A L K$ rearrangement, circulating tumor cells, targeted therapy, non-small-cell lung cancer, predictive biomarker
In the past decade, the treatment of non-small-cell lung cancer (NSCLC) has considerably shifted with the emergence of rationally targeted therapies for a subset of molecularly defined lung cancers. NSCLCs and in particular adenocarcinoma, the most frequent histologic subtype, have been segmented into clinically relevant molecular subsets according to a classification based on multiple so-called oncogenic "driver" alterations (Figure 1A) (1). These somatic aberrations occur in genes that encode signaling proteins crucial for tumor proliferation and survival. Tumors harboring these mutant oncogenes may be systematically identified and targeted specifically using tyrosine kinase inhibitor (TKI) therapies that ensure dramatic and durable clinical benefit. The first example of a clinically relevant NSCLC driver oncogene was the identification of somatic mutations in the epidermal growth factor receptor (EGFR) gene (2-4).Common EGFR alterations (the L858R point mutation and exon 19 deletions) are present in $10-30 \%$ of patients with NSCLC and confer sensitivity to gefitinib, erlotinib, and afatinib. As first-line treatment, EGFR inhibitors can produce overall response rates (ORR) of 75\% in selected NSCLC patients (5).

Similarly to EGFR mutations, the $A L K$-gene rearrangement defines a unique molecular subset in $3-7 \%$ of NSCLC patients (6). ALK-gene rearrangement involves the anaplastic lymphoma kinase $(A L K)$ gene and, most often, the echinoderm microtubuleassociated protein-like 4 (EML4) loci which both map to the short arm of the human chromosome 2 in opposite directions $(7,8)$ (Figure 1B). Several different in-frame fusion variants of EML4-ALK have been described with different EML4 breakpoints. However, all fusion variants contain the same C-terminal domain, which confers a gain of function resulting in constitutively active fusion proteins with potent transforming activity. The clinical characteristics of NSCLC patients that are positive for EML4-ALK variants are similar to those of who harbor activating mutations in the EGFR gene: both groups of patients tend to manifest an adenocarcinoma histological subtype and to be non or light smokers (9). The discovery that the EML4-ALK fusion protein was a potent oncogenic driver in NSCLC rapidly fueled the development of the multi-targeted TKI crizotinib, and accelerated its FDA approval for the treatment of patients with advanced $A L K$-positive NSCLC. Two studies have since shown an ORR of $60 \%$ and a median progression free survival (PFS) of 8-9 months in $A L K$ positive NSCLC patients receiving crizotinib (10). Another study compared treatment with crizotinib to chemotherapy in ALKpositive NSCLC patients and showed that the PFS was longer for patients receiving crizotinib (7.7 months) than for those treated with chemotherapy (3 months) (11). Despite this high response rate in $A L K$-rearranged NSCLC, most patients develop resistance to crizotinib, typically within 1 year. Next generation ALK inhibitors with potentially improved efficacy and selectivity compared to crizotinib are currently being developed to overcome this resistance to crizotinib. In a recent phase I study, ceritinib demonstrated marked anti-tumor activity in both crizotinib-relapsed and crizotinib-naive patients (12).

Prospective molecular profiling of NSCLC is now performed in routine clinical practice to identify oncogenic "driver" abnormalities and to screen eligible patients for targeted TKI therapies. Tumor tissue may be difficult to obtain in advanced/metastatic NSCLC patients for whom surgery is rarely a component of the treatment strategy. The molecular characteristics or biomarkers 


\section{A}

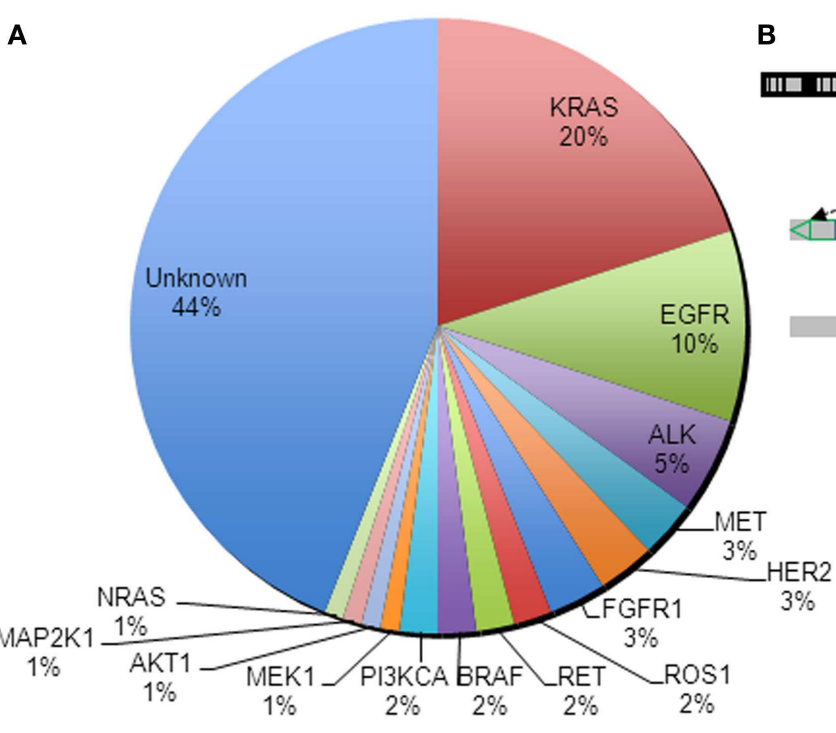

C

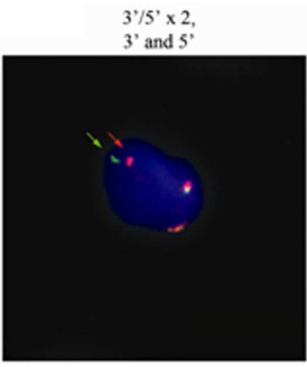

D
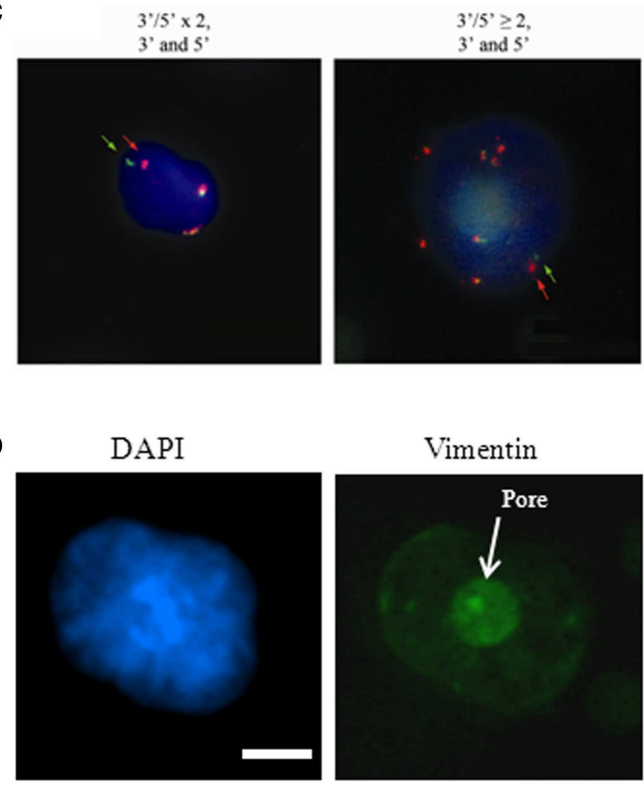

Vimentin

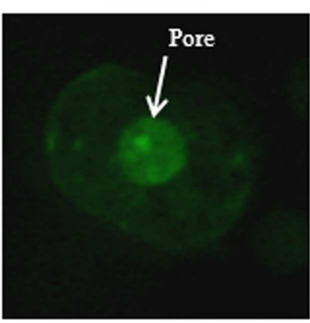

FIGURE 1 | Molecular characterization of CTC in ALK-rearranged non-small-cell lung cancer. (A) Pie chart of NSCLC mutations and scheme representation of $A L K$ rearrangement. Percentage of known somatic mutations in oncogenic drivers in NSCLC. Pie chart of NSCLC mutations. (B) Scheme of EML4-ALK rearrangement. The two genes are located on chromosome 2 in position 2 p21 and 2p23, respectively for $E M L 4$ and $A L K$. The rearrangement is the result of a chromosomal inversion. (C) Examples of $A L K$-gene abnormalities detected by FA-FISH. $A L K$-rearranged CTC with an ALK native copy (yellow signal) and an

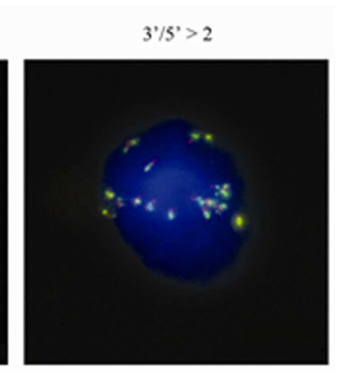

Merge

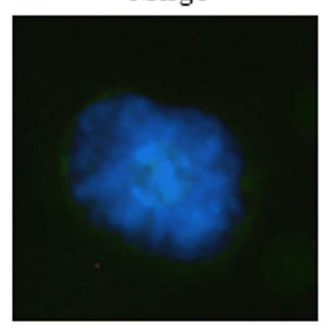

$2 p 21 \quad 2 p 23$

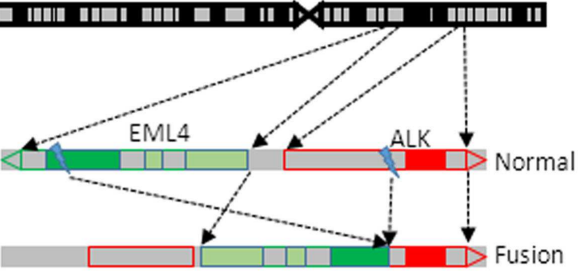

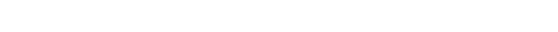


ALK assay) enables to detect $A L K$ rearrangement with a high sensitivity and concordance when compared to FISH results, and has the advantage to be automated, faster, and less expensive than
FISH (13). Treatment with crizotinib was FDA approved with a companion diagnostic test, the Vysis $A L K$ break apart FISH probe kit (Abott molecular). Finding alternatives to a tumor biopsy and

Table 1 | Numbers and percentages of ALK-rearranged cells in tumor and in CTCs of ALK-positive and ALK-negative patients.

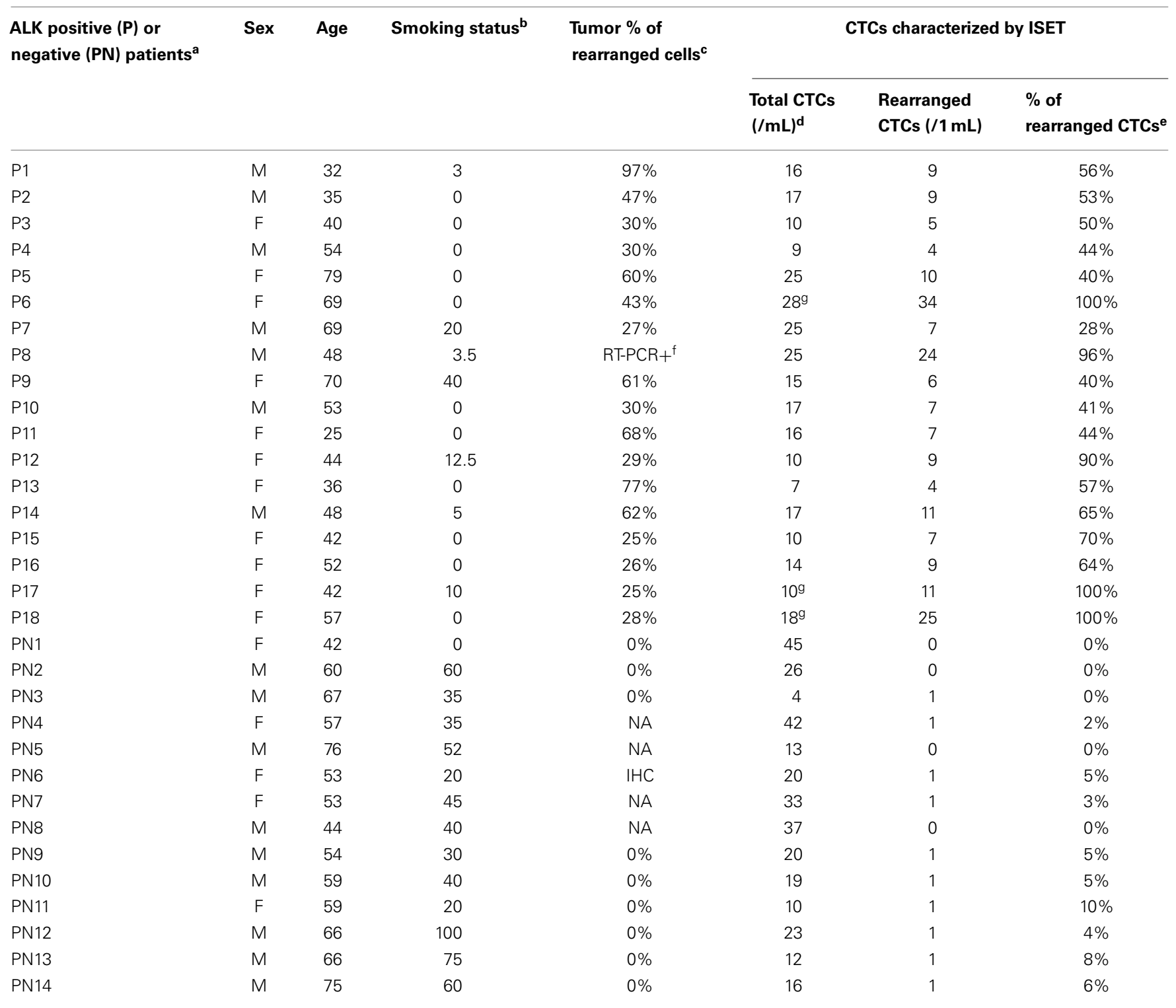

ALK, anaplastic lymphoma kinase; CTC, circulating tumor cell; FISH, fluorescence in situ hybridization; NA, not available; RT-PCR, reverse transcription polymerase chain reaction.

${ }^{a}$ All patients have metastatic disease.

${ }^{b}$ Number of pack-years. All patients are former or never smokers (0: never smokers).

'Percentage of rearranged tumor cells determined by FISH in tumor samples.

${ }^{d}$ Total numbers of CTCs per milliliter were calculated as the mean of CTCs identified by combining a four-color immunofluorescent staining with cytomorphological examination in $3 \times 1 \mathrm{~mL}$ of blood.

e Percentage of ALK-rearranged CTCS is the proportion of ALK-rearranged CTCS determined by FA-FISH among total numbers of CTCS determined in independent experiments by combining a four-color immunofluorescent staining with cytomorphological examination.

'The biopsy was negative by FISH but positive by RT-PCR.

${ }^{g}$ In this three patients, numbers of ALK-rearranged CTCs were slightly greater to the number of total CTCs identified by phenotypic analysis. This difference is due to the fact that numbers of CTCs may differ between each spot of the filter. 
more effective means to diagnose an $A L K$ rearrangement is a critical issue in order to identify NSCLC patients who may benefit from an ALK inhibitor treatment.

Molecular characterization of circulating tumor cells (CTCs) may inform on the status of predictive biomarkers for drug sensitivity and therapy selection. CTCs are, however, very rare events occurring at rates, as low as one cell per $10^{6}$ or $10^{7}$ leukocytes. Most methods of CTC detection rely on the combination of two successive steps, an initial enrichment process followed by CTC detection so as to increase the sensitivity of the assay (14). Numerous technical efforts have been made to reliably detect and quantify CTCs, although the development of a universal assay has proven quite difficult. The major technical challenges for CTC detection are due to the rarity of CTCs and their high degree of phenotypical and molecular heterogeneity. Using the CellSearch platform, which is based on the detection of epithelial cells expressing EpCAM, CTCs levels have been observed to be prognostic in various metastatic solid tumors including NSCLC and SCLC. Using an enrichment technique based on blood filtration (ISET, isolation by size epithelial tumor cells), the prognostic value of CTCs was also reported in patients with resected NSCLC. We and others groups have reported that CTCs are identified in higher numbers using the ISET technique compared to the CellSearch method in NSCLC most likely due to the fact that CTCs expressing markers of epithelial-mesenchymal transition (EMT) and that have lost epithelial features are missed by CellSearch (15). In spite of technical difficulties, a few studies have demonstrated the feasibility of CTC assays for predictive biomarker detection. Two groups including our own have reported the feasibility of detecting $A L K$ rearrangement from CTCs enriched by filtration in patients with $A L K$-positive NSCLC $(16,17)$. Ilie et al. reported the detection of $A L K$ rearrangement and strong ALK protein expression by IHC in CTCs from five patients with $A L K$-rearranged NSCLC. FISH and IHC were negative in CTCs from 82 NSCLC patients whose tumors did not harbor $A L K$ rearrangement. In order to exploit CTCs as predictive biomarkers of personalized treatments, our group developed a FISH method on filters (filter adaptedFISH, FA-FISH) that was optimized for high cell recovery. By combining blood filtration and FA-FISH, we demonstrated that $A L K$-rearranged CTCs could be detected in a cohort of $18 A L K$ positive NSCLC patients (17). All $18 A L K$-positive patients had four or more $A L K$-rearranged CTCs per milliliter of blood while no or only one $A L K$-rearranged CTC was detected in $14 A L K$ negative patients (Table 1). Furthermore, all CTCs harbored a unique $A L K$-rearrangement pattern consisting in the $3^{\prime} 5^{\prime}$ break apart of $A L K$ probes whereas heterogeneous rearrangement patterns were present within the tumor. This unique $3^{\prime} 5^{\prime}$ pattern was present in CTCs harboring either a single copy of $A L K$ or a gain of native $A L K$ copies (Figure 1C). CTCs harboring an isolated red signal pattern were never detected in $A L K$-positive patients, even when isolated red signals were exclusively present in the tumor biopsies. The split rearrangement pattern was therefore detected in CTCs regardless of the frequency of tumor cells harboring this rearrangement in the tumor tissue. $A L K$-rearranged CTCs harboring this unique rearrangement expressed a mesenchymal phenotype, suggesting that these cells may have derived from the clonal selection of tumor cells harboring greater invasive and migratory properties (Figure 1D). In this study, we also demonstrated that monitoring quantitative and qualitative changes of CTCs with distinct $A L K$ abnormalities pattern was feasible in patients undergoing ALK inhibitor therapy.

By demonstrating that $A L K$ rearrangement can be reliably detected in the CTCs of $A L K$-positive NSCLC patients, these two studies provide new perspectives for the diagnosis of $A L K$ positive patients eligible for treatment with ALK inhibitors. These non-invasive molecular analyses performed on CTCs could be easily repeated at different time-points during treatment and could help to guide therapeutic decisions in a patient's treatment course. Single cell analyses of CTCs captured on filters at the time of disease progression are also anticipated to help characterize resistant subclones and mechanisms of resistance to ALK inhibitors.

\section{REFERENCES}

1. Shames DS, Wistuba II. The evolving genomic classification of lung cancer. $J$ Pathol (2014) 232(2):121-33. doi:10.1002/path.4275

2. Pao W, Miller V, Zakowski M, Doherty J, Politi K, Sarkaria I, et al. EGF receptor gene mutations are common in lung cancers from "never smokers" and are associated with sensitivity of tumors to gefitinib and erlotinib. Proc Natl Acad Sci U S A (2004) 101(36):13306-11. doi:10.1073/pnas.0405220101

3. Paez JG, Janne PA, Lee JC, Tracy S, Greulich H, Gabriel S, et al. EGFR mutations in lung cancer: correlation with clinical response to gefitinib therapy. Science (2004) 304(5676):1497-500. doi:10.1126/science.1099314

4. Lynch TJ, Bell DW, Sordella R, Gurubhagavatula S, Okimoto RA, Brannigan BW, et al. Activating mutations in the epidermal growth factor receptor underlying responsiveness of non-small-cell lung cancer to gefitinib. N Engl J Med (2004) 350(21):2129-39. doi:10.1056/NEJMoa040938

5. Rosell R, Carcereny E, Gervais R, Vergnenegre A, Massuti B, Felip E, et al. Erlotinib versus standard chemotherapy as first-line treatment for European patients with advanced EGFR mutation-positive non-small-cell lung cancer (EURTAC): a multicentre, open-label, randomised phase 3 trial. Lancet Oncol (2012) 13(3):239-46. doi:10.1016/S1470-2045(11)70393-X

6. Kwak EL, Bang YJ, Camidge DR, Shaw AT, Solomon B, Maki RG, et al. Anaplastic lymphoma kinase inhibition in non-small-cell lung cancer. N Engl J Med (2010) 363(18):1693-703. doi:10.1056/NEJMoa1006448

7. Soda M, Choi YL, Enomoto M, Takada S, Yamashita Y, Ishikawa S, et al. Identification of the transforming EML4-ALK fusion gene in non-small-cell lung cancer. Nature (2007) 448(7153):561-6. doi:10.1038/nature05945

8. Horn L, Pao W. EML4-ALK: honing in on a new target in non-small-cell lung cancer. J Clin Oncol (2009) 27(26):4232-5. doi:10.1200/JCO.2009.23.6661

9. Camidge DR, Kono SA, Flacco A, Tan AC, Doebele RC, Zhou Q, et al. Optimizing the detection of lung cancer patients harboring anaplastic lymphoma kinase (ALK) gene rearrangements potentially suitable for ALK inhibitor treatment. Clin Cancer Res (2010) 16(22):5581-90. doi:10.1158/1078-0432.CCR-10-0851

10. Camidge DR, Bang YJ, Kwak EL, Iafrate AJ, Varella-Garcia M, Fox SB, et al. Activity and safety of crizotinib in patients with ALK-positive non-small-cell lung cancer: updated results from a phase 1 study. Lancet Oncol (2012) 13(10):1011-9. doi:10.1016/S1470-2045(12)70344-3

11. Shaw AT, Kim DW, Nakagawa K, Seto T, Crino L, Ahn MJ, et al. Crizotinib versus chemotherapy in advanced ALK-positive lung cancer. N Engl J Med (2013) 368(25):2385-94. doi:10.1056/NEJMoa1214886

12. Shaw AT, Engelman JA. Ceritinib in ALK-rearranged non-small-cell lung cancer. N Engl J Med (2014) 370(26):2537-9. doi:10.1056/NEJMc1404894

13. Wang J, Cai Y, Dong Y, Nong J, Zhou L, Liu G, et al. Clinical characteristics and outcomes of patients with primary lung adenocarcinoma harboring ALK rearrangements detected by FISH, IHC, and RT-PCR. PLoS One (2014) 9(7):e101551. doi:10.1371/journal.pone.0101551

14. Mostert B, Sleijfer S, Foekens JA, Gratama JW. Circulating tumor cells (CTCs): detection methods and their clinical relevance in breast cancer. Cancer Treat Rev (2009) 35(5):463-74. doi:10.1016/j.ctrv.2009.03.004

15. Lecharpentier A, Vielh P, Perez-Moreno P, Planchard D, Soria JC, Farace F. Detection of circulating tumour cells with a hybrid (epithelial/mesenchymal) phenotype in patients with metastatic non-small cell lung cancer. Br J Cancer (2011) 105(9):1338-41. doi:10.1038/bjc.2011.405 
16. Ilie M, Long E, Butori C, Hofman V, Coelle C, Mauro V, et al. ALKgene rearrangement: a comparative analysis on circulating tumour cells and tumour tissue from patients with lung adenocarcinoma. Ann Oncol (2012) 23(11):2907-13. doi:10.1093/annonc/mds137

17. Pailler E, Adam J, Barthelemy A, Oulhen M, Auger N, Valent A, et al. Detection of circulating tumor cells harboring a unique ALK rearrangement in ALK-positive non-small-cell lung cancer. J Clin Oncol (2013) 31(18):2273-81. doi:10.1200/JCO.2012.44.5932

Conflict of Interest Statement: The authors declare that the research was conducted in the absence of any commercial or financial relationships that could be construed as a potential conflict of interest.
Received: 04 August 2014; accepted: 29 September 2014; published online: 05 November 2014.

Citation: Faugeroux V, Pailler E, Auger N, Taylor M and Farace F (2014) Clinical utility of circulating tumor cells in ALK-positive non-small-cell lung cancer. Front. Oncol. 4:281. doi: 10.3389/fonc.2014.00281

This article was submitted to Thoracic Oncology, a section of the journal Frontiers in Oncology.

Copyright (c) 2014 Faugeroux, Pailler, Auger, Taylor and Farace. This is an open-access article distributed under the terms of the Creative Commons Attribution License (CC $B Y)$. The use, distribution or reproduction in other forums is permitted, provided the original author(s) or licensor are credited and that the original publication in this journal is cited, in accordance with accepted academic practice. No use, distribution or reproduction is permitted which does not comply with these terms. 